\title{
ER Stress, UPR Activation and the Inflammatory Response to Viral Infection
}

\author{
Mara Cirone ${ }^{1,2}$ (D)
}

check for

updates

Citation: Cirone, M. ER Stress, UPR Activation and the Inflammatory Response to Viral Infection. Viruses 2021, 13, 798. https://doi.org/ 10.3390/v13050798

Academic Editor: Rod Russell

Received: 24 March 2021

Accepted: 28 April 2021

Published: 29 April 2021

Publisher's Note: MDPI stays neutral with regard to jurisdictional claims in published maps and institutional affiliations.

Copyright: (c) 2021 by the author. Licensee MDPI, Basel, Switzerland. This article is an open access article distributed under the terms and conditions of the Creative Commons Attribution (CC BY) license (https:/ / creativecommons.org/licenses/by/ $4.0 /)$.
1 Department of Experimental Medicine, La Sapienza University of Rome, Viale Regina Elena 324, 00185 Rome, Italy; mara.cirone@uniroma1.it

2 Laboratory Affiliated to Istituto Pasteur Italia-Fondazione Cenci Bolognetti, 00185 Rome, Italy

\begin{abstract}
The response to invading pathogens such as viruses is orchestrated by pattern recognition receptor (PRR) and unfolded protein response (UPR) signaling, which intersects and converges in the activation of proinflammatory pathways and the release of cytokines and chemokines that harness the immune system in the attempt to clear microbial infection. Despite this protective intent, the inflammatory response, particularly during viral infection, may be too intense or last for too long, whereby it becomes the cause of organ or systemic diseases itself. This suggests that a better understanding of the mechanisms that regulate this complex process is needed in order to achieve better control of the side effects that inflammation may cause while potentiating its protective role. The use of specific inhibitors of the UPR sensors or PRRs or the downstream pathways activated by their signaling could offer the opportunity to reach this goal and improve the outcome of inflammation-based diseases associated with viral infections.
\end{abstract}

Keywords: viruses; PPRs; UPR; inflammation

\section{Viruses, PPRs, and Inflammation}

Viruses entering into target cells are promptly recognized by different classes of molecules identified as PRRs, which are mainly represented by the family of Toll-like receptors, nucleoside-binding oligomerization domain containing-like receptors (NLRs), C-type lectin receptors (CRLs), and the cGAS/STING pathway [1,2]. PRRs sense the pathogen components, called pathogen-associated molecular patterns (PAMPs), and trigger a signaling cascade, which after the recruitment of adapter molecules, culminates in the activation of transcription factors such as nuclear factor (NF) kB, activator protein [3] 1 and signal transducer and activator of transcription (STAT) 3, promoting the release of type I interferon (IFN) and proinflammatory cytokines such as IL-1 $\beta$, IL-6, TNF $\alpha$, and chemokines. Mitogen-activated protein kinases (MAPKs), and interferon regulatory factors (IRFs) may be also activated by PRR signaling and strongly contribute to cytokine release [4]. However, to balance inflammation, anti-inflammatory and immune-suppressive cytokines such as IL10 are also produced downstream of PRRs. Epithelial cells and immune cells, particularly those present at the mucosal barriers, are equipped with several PRRs in order to prevent the potential insults that invading pathogens could induce. In addition, other immune cells are recruited from blood to the infected tissue by chemokines and other chemotactic factors, amplifying the inflammatory response. In some cases, inflammation may be so intense that it creates pathological consequences for the infected host and paradoxically leads to an impairment of immune function, exacerbating the damage that viral infection mediates [5].

\section{Viruses, ER Stress, UPR Activation and Inflammation}

In addition to PRR signaling, viral infection activates the unfolded protein response (UPR) [6]. This response is initiated by the activation of inositol-requiring enzyme 1 (IRE1) $\alpha$, PKR-like endoplasmic reticulum kinase (PERK), and activating transcription factor 
(ATF) 6, the three main UPR sensors, which in unstressed conditions, bind to 78-kDa glucose-regulated protein (GRP78), also called BIP, which maintains them in an inactive state. The accumulation of unfolded or misfolded proteins into the ER, which causes ER stress, attracts BIP, detaching it from the three sensors that are activated [7]. Viral infection, especially during the replicative cycle, induces the production of a high quantity of viral proteins, which accumulate in the ER, overwhelming its folding capacity. This causes UPR activation, although viruses may trigger such responses independently of ER stress through the viral kinase PKR or by hijacking the ER membranes to accomplish their replicative cycle $[8,9]$. UPR can be considered an adaptive process, as it s. Indeed, UPR leads to the reduction of protein translation through the activation of the PERKeukaryotic translation-initiation factor (eIF) 2 axis, increases ER chaperone transcription, mRNA degradation, and protein catabolism via endoplasmic-reticulum-associated protein degradation (ERAD) or macroautophagy through IRE1 $\alpha$ [10]. Macroautophagy plays an essential role in relieving cells from stress; besides IRE1 $\alpha$, the other two UPR sensors PERK and ATF6 are also able to trigger this catabolic process [11]. However, macroautophagy or the selective forms of autophagy such as xenophagy are often dysregulated by viruses as a smart strategy to prevent them reaching the lysosomes, where they may be eliminated by the lysosomal proteases [12]. By reducing autophagy, viruses may exacerbate ER stress and this may shift the prosurvival function of UPR into cell death, an effect that can be advantageous for viruses if the infected cells belong to the immune system [13-16]. Interestingly, activated ER stress and UPR may contribute to the production of proinflammatory cytokines. The activation of IRE1 $\alpha$ binds to TNF receptor-associated factor (TRAF) 2 and phosphorylates IkB, leading to the activation of NF- $\mathrm{kB}$ [17]. This transcription factor, which has a central role in the inflammatory response, can also be activated by ATF6 via AKT and by the PERK/eIF2 $\alpha$ axis, which by inhibiting protein translation, reduces the expression of NF- $\mathrm{kB}$ inhibitor IkB. The c-Jun N-terminal kinase (JNK), p38 and extracellular signal-regulated kinase (ERK) 1/2, and mitogen-activated protein kinases (MAPKs) that are strongly involved in the control of cytokine release may also be activated by the three UPR sensors [18]. Indeed, UPR activation may occur independently of the presence of microrganisms, such as in the case of the ER stressor thapsigargin, which induces sterile inflammation [19]. The production of reactive oxygen species [20] generated during ER stress and the protein re-folding process contributes to the UPR-mediated activation of NF- $\mathrm{KB}$ and MAPKs. In addition, it has been reported that the UPR sensors may bind to genetic cytokine regulatory elements, directly affecting the production of inflammatory, antiviral, and immune-suppressive cytokines [21]. Importantly, sterile ER stress or single PRR stimulation induce a mild inflammatory response that requires both PRR ligation and ER stress to occur concomitantly to become intense inflammation. This is also because PRR and UPR signaling intersects at multiple levels and converges in the activation of the major proinflammatory transcription factors [22,23].

\section{UPR and PRR Cross-Talk}

Interestingly, viruses may activate UPR through PRR signaling independently of ER stress. For example, TLR2 and TLR4 signaling has been reported to activate IRE1 $\alpha$ through TNF-receptor-associated factor (TRAF) 6 and nicotinammide adenina dinucleotide fosfato (NADPH) oxidase 2 (NOX2) [24]. NOX activation by viruses, together with the reduction of the antioxidant response, results in an increase of ROS that enhances the inflammatory response. However, the PERK sensor may also trigger the antioxidant response through the activation of nuclear factor erythroid 2-related factor (NRF) 2, balancing ROS levels [25]. Moreover, both TLR-signaling and the PERK sensor activate STAT3, which strongly contributes to the production of IL- 6 and IL-10, cytokines that in turn keep STAT3 phosphorylated in a positive regulatory circuit [26]. From these evidences, it appears that UPR and PRR signaling intersects and cooperates in inducing the production of antiviral, proinflammatory, and anti-inflammatory cytokines, as well as ROS. The inflammatory response in the course of viral infection may be particularly strong, as it concomitantly 
affects both PRR and UPR signaling in either an independent or interconnected fashion. This suggests that to mitigate excessive inflammation and prevent the local or systemic destructive effects that may occur during viral infection, the selective inhibition and activation of UPR sensors or PRR could represent a potential strategy.

\section{Possible Consequences of Excessive Inflammation in Response to Viral Infection}

Some respiratory viruses, such as influenza [27] or coronaviruses [28], or herpesviruses, such as Epstein-Barr virus (EBV) or human cytomegalovirus (HCMV), when reactivating from latency in immune-compromised patients, infect epithelial cells, such as alveolar or bronchial cells, as well as endothelial and immune cells, leading to a massive proinflammatory cytokine release, known as "cytokine storm syndrome" [29]. This huge amount of cytokines can worsen the tissue damage induced by viral infection and alter the functions of uninfected bystander cells in the site of injury. Cytokine-damaged endothelial cells may result in activation of the coagulation cascade, given the strong interconnection that occurs between inflammation and the activation of the coagulation cascade [30]. The functions of fibroblasts may also be altered by the inflammatory milieu, as it stimulates their trans-differentiation into myofibroblasts, promoting fibrosis and thus aggravating tissue dysfunction [31]. The interplay between infected and uninfected cells mediated by the release of inflammatory cytokines is shown in Figure 1.

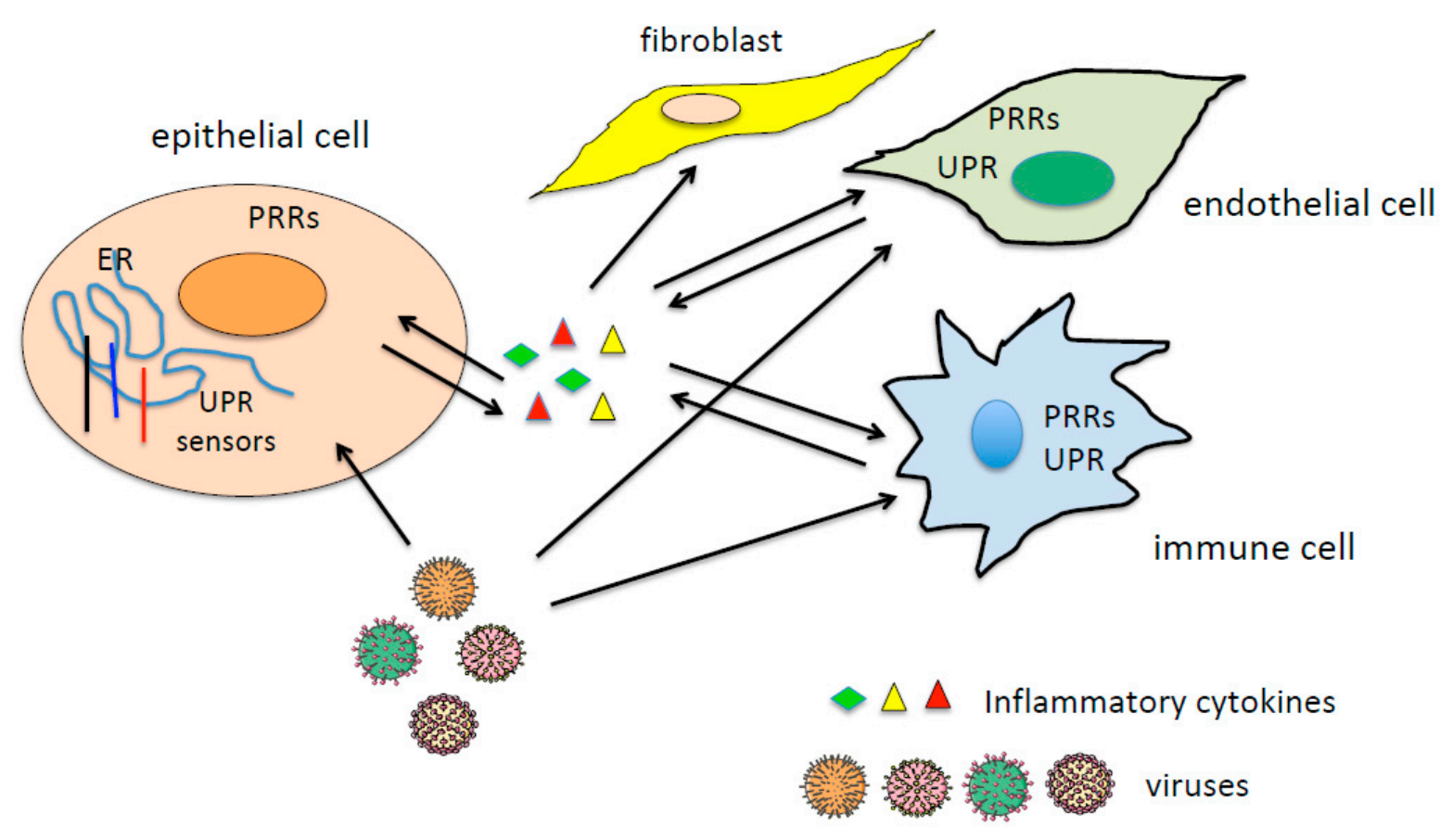

Figure 1. PRR and UPR signaling induce cytokine release that may spread the effects.

Finally, cytokines may be transported far from the site of production by the blood stream, causing damage in several organs and tissues and inducing systemic effects. These events are reported to occur in some patients following infection by the new coronavirus SARS-CoV2, which causes the pandemic disease known as COVID-19 [32].

\section{Targeting UPR or PRR Signaling to Mitigate Excessive Inflammation in the Course of Viral Infections}

Although the role of UPR activation in the release of proinflammatory, antiviral, and anti-inflammatory cytokines during viral infection is still under investigation, there are several studies showing that it contributes to inflammation [21,33]. The example of some viruses being able to activate UPR or one of its arms to enhance cytokine production is reported in Table 1. 
Therefore, to mitigate the destructive process of inflammation and improve the efficiency of the immune response, the selective inhibition of UPR sensors or PRR signaling could be exploited. In the first case, pharmacological inhibitors of IRE1 $\alpha$, PERK, and ATF6 molecules such as $4 \mu 8 \mathrm{c}$, Ceapin, or GSK2606414, respectively, could be used, although the side effects that they could cause must be considered [20,34]. Indeed, less toxic UPR inhibitors are being developed and some of them are in preclinical trials against cancers, such as multiple myeloma [3]. To control PRR signaling, a promising strategy could be to use the antagonists of TLR4, such as Eritoran. Targeting this particular TLR could be particularly efficient in restraining the destructive excess of inflammation, as TLR4, besides by PAMPs, it may be activated by molecules released following viral-induced tissue damage, called damage-associated molecular patterns (DAMPs) [35]. Therefore, it appears that tuning PRR or UPR signaling may help to reduce the severity of complications occurring in the course of viral diseases, particularly COVID-19 [36]. Regarding herpesviruses, the majority of which are ubiquitous viruses, they are known to infect and persist in several cell types, and the chronic infection that they cause may induce long lasting or chronic inflammation in several tissues. This facilitates the onset of a variety of inflammation-based diseases ranging from gastritis, inflammatory bowel diseases, autoimmune diseases, neurodegenerative diseases, and cancer [33,37-39]. Other completely different viruses such as hepatitis viruses may also cause diseases, to whose pathogenesis the inflammatory response strongly contributes. Therefore, a better understanding of the mechanisms regulating the intensity and duration of the inflammatory response could help to find strategies to selectively control the activation of PRRs and UPR signaling or their downstream activated pathways, restraining the side effects of inflammation while preserving or even potentiating its protective role, improving the outcome of virus-associated diseases.

Table 1. Example of viruses that promote inflammation by activating UPR.

\begin{tabular}{|c|c|c|c|}
\hline Virus & UPR/UPR Arm & Inflammatory Molecules & References \\
\hline Hepatitis B virus (HBV) & eIF $2 \alpha /$ ATF 4 & Cox-2 & [40] \\
\hline Dengue virus (DENV) & PERK/Nrf2 & TNF- $\alpha$ & [41] \\
\hline \multirow{2}{*}{$\begin{array}{c}\text { Kaposi's sarcoma-associated } \\
\text { herpesvirus (KSHV) }\end{array}$} & IRE1a & TNF- $\alpha$, IL-6, IL-10, IL-8, VEGF & [33] \\
\hline & PERK & CCL-2 & [33] \\
\hline SARS-CoV-2 & ER stress/UPR & IL-6, IL-1b & [36] \\
\hline
\end{tabular}

Funding: AIRC IG 2019-23040.

Institutional Review Board Statement: Not applicable.

Informed Consent Statement: Not applicable.

Data Availability Statement: Not applicable.

Conflicts of Interest: The author declare no conflict of interest.

\section{References}

1. Lester, S.N.; Li, K. Toll-like receptors in antiviral innate immunity. J. Mol. Biol. 2014, 426, 1246-1264. [CrossRef] [PubMed]

2. Sabbah, A.; Chang, T.H.; Harnack, R.; Frohlich, V.; Tominaga, K.; Dube, P.H.; Xiang, Y.; Bose, S. Activation of innate immune antiviral responses by Nod2. Nat. Immunol. 2009, 10, 1073-1080. [CrossRef]

3. Almanza, A.; Carlesso, A.; Chintha, C.; Creedican, S.; Doultsinos, D.; Leuzzi, B.; Luis, A.; McCarthy, N.; Montibeller, L.; More, S.; et al. Endoplasmic reticulum stress signalling_from basic mechanisms to clinical applications. FEBS J. 2019, 286, 241-278. [CrossRef] [PubMed]

4. Takeuchi, O.; Akira, S. Pattern recognition receptors and inflammation. Cell 2010, 140, 805-820. [CrossRef]

5. Larsen, S.B.; Cowley, C.J.; Fuchs, E. Epithelial cells: Liaisons of immunity. Curr. Opin. Immunol. 2020, 62, 45-53. [CrossRef] [PubMed]

6. Reverendo, M.; Mendes, A.; Arguello, R.J.; Gatti, E.; Pierre, P. At the crossway of ER-stress and proinflammatory responses. FEBS J. 2019, 286, 297-310. [CrossRef] [PubMed] 
7. Corazzari, M.; Gagliardi, M.; Fimia, G.M.; Piacentini, M. Endoplasmic Reticulum Stress, Unfolded Protein Response, and Cancer Cell Fate. Front. Oncol. 2017, 7, 78. [CrossRef] [PubMed]

8. Chan, S.W. The unfolded protein response in virus infections. Front. Microbiol. 2014, 5, 518. [CrossRef]

9. Choi, J.A.; Song, C.H. Insights Into the Role of Endoplasmic Reticulum Stress in Infectious Diseases. Front. Immunol. 2019, 10, 3147. [CrossRef]

10. Hetz, C.; Zhang, K.; Kaufman, R.J. Mechanisms, regulation and functions of the unfolded protein response. Nat. Rev. Mol. Cell Biol. 2020, 21, 421-438. [CrossRef]

11. Cirone, M. Perturbation of bulk and selective macroautophagy, abnormal UPR activation and their interplay pave the way to immune dysfunction, cancerogenesis and neurodegeneration in ageing. Ageing Res. Rev. 2020, 58, 101026. [CrossRef]

12. Cirone, M. EBV and KSHV Infection Dysregulates Autophagy to Optimize Viral Replication, Prevent Immune Recognition and Promote Tumorigenesis. Viruses 2018, 10, 599. [CrossRef]

13. Santarelli, R.; Granato, M.; Pentassuglia, G.; Lacconi, V.; Gilardini Montani, M.S.; Gonnella, R.; Tafani, M.; Torrisi, M.R.; Faggioni, A.; Cirone, M. KSHV reduces autophagy in THP-1 cells and in differentiating monocytes by decreasing CAST/calpastatin and ATG5 expression. Autophagy 2016, 12, 2311-2325. [CrossRef] [PubMed]

14. Gilardini Montani, M.S.; Santarelli, R.; Granato, M.; Gonnella, R.; Torrisi, M.R.; Faggioni, A.; Cirone, M. EBV reduces autophagy, intracellular ROS and mitochondria to impair monocyte survival and differentiation. Autophagy 2019, 15, 652-667. [CrossRef] [PubMed]

15. Romeo, M.A.; Gilardini Montani, M.S.; Benedetti, R.; Giambelli, L.; D’Aprile, R.; Gaeta, A.; Faggioni, A.; Cirone, M. The cross-talk between STAT1/STAT3 and ROS up-regulates PD-L1 and promotes the release of pro-inflammatory/immune suppressive cytokines in primary monocytes infected by HHV-6B. Virus Res. 2021, 292, 198231. [CrossRef] [PubMed]

16. Romeo, M.A.; Gilardini Montani, M.S.; Falcinelli, L.; Gaeta, A.; Nazzari, C.; Faggioni, A.; Cirone, M. HHV-6B reduces autophagy and induces ER stress in primary monocytes impairing their survival and differentiation into dendritic cells. Virus Res. 2019, 273, 197757. [CrossRef] [PubMed]

17. Kaneko, M.; Niinuma, Y.; Nomura, Y. Activation signal of nuclear factor-kappa B in response to endoplasmic reticulum stress is transduced via IRE1 and tumor necrosis factor receptor-associated factor 2. Biol. Pharm. Bull. 2003, 26, 931-935. [CrossRef]

18. Chen, L.; Deng, H.; Cui, H.; Fang, J.; Zuo, Z.; Deng, J.; Li, Y.; Wang, X.; Zhao, L. Inflammatory responses and inflammationassociated diseases in organs. Oncotarget 2018, 9, 7204-7218. [CrossRef]

19. Kmonickova, E.; Canova, N.K.; Farghali, H.; Holy, A.; Zidek, Z. Modulator of intracellular Ca(2+), thapsigargin, interferes with in vitro secretion of cytokines and nitric oxide. Biomed. Pap. Med. Fac. Univ. Palacky Olomouc Czech. Repub. 2005, 149, 321-324. [CrossRef]

20. Mahameed, M.; Wilhelm, T.; Darawshi, O.; Obiedat, A.; Tommy, W.S.; Chintha, C.; Schubert, T.; Samali, A.; Chevet, E.; Eriksson, L.A.; et al. The unfolded protein response modulators GSK2606414 and KIRA6 are potent KIT inhibitors. Cell Death Dis. 2019, 10, 300. [CrossRef]

21. Smith, J.A. Regulation of Cytokine Production by the Unfolded Protein Response; Implications for Infection and Autoimmunity. Front. Immunol. 2018, 9, 422. [CrossRef] [PubMed]

22. Janssens, S.; Pulendran, B.; Lambrecht, B.N. Emerging functions of the unfolded protein response in immunity. Nat. Immunol. 2014, 15, 910-919. [CrossRef] [PubMed]

23. Kim, S.; Joe, Y.; Surh, Y.J.; Chung, H.T. Differential Regulation of Toll-Like Receptor-Mediated Cytokine Production by Unfolded Protein Response. Oxid. Med. Cell. Longev. 2018, 2018, 9827312. [CrossRef] [PubMed]

24. Martinon, F.; Chen, X.; Lee, A.H.; Glimcher, L.H. TLR activation of the transcription factor XBP1 regulates innate immune responses in macrophages. Nat. Immunol. 2010, 11, 411-418. [CrossRef]

25. Cullinan, S.B.; Diehl, J.A. Coordination of ER and oxidative stress signaling: The PERK/Nrf2 signaling pathway. Int. J. Biochem. Cell Biol. 2006, 38, 317-332. [CrossRef]

26. Meares, G.P.; Liu, Y.; Rajbhandari, R.; Qin, H.; Nozell, S.E.; Mobley, J.A.; Corbett, J.A.; Benveniste, E.N. PERK-dependent activation of JAK1 and STAT3 contributes to endoplasmic reticulum stress-induced inflammation. Mol. Cell. Biol. 2014, 34, 3911-3925. [CrossRef]

27. Lin, X.; Wang, R.; Zou, W.; Sun, X.; Liu, X.; Zhao, L.; Wang, S.; Jin, M. The Influenza Virus H5N1 Infection Can Induce ROS Production for Viral Replication and Host Cell Death in A549 Cells Modulated by Human Cu/Zn Superoxide Dismutase (SOD1) Overexpression. Viruses 2016, 8, 13. [CrossRef]

28. Yoshikawa, T.; Hill, T.; Li, K.; Peters, C.J.; Tseng, C.T. Severe acute respiratory syndrome (SARS) coronavirus-induced lung epithelial cytokines exacerbate SARS pathogenesis by modulating intrinsic functions of monocyte-derived macrophages and dendritic cells. J. Virol. 2009, 83, 3039-3048. [CrossRef]

29. Bonizzoli, M.; Arvia, R.; di Valvasone, S.; Liotta, F.; Zakrzewska, K.; Azzi, A.; Peris, A. Human herpesviruses respiratory infections in patients with acute respiratory distress (ARDS). Med. Microbiol. Immunol. 2016, 205, 371-379. [CrossRef]

30. Foley, J.H.; Conway, E.M. Cross Talk Pathways Between Coagulation and Inflammation. Circ. Res. 2016, 118, 1392-1408. [CrossRef]

31. Evans, C.E.; Zhao, Y.Y. Impact of thrombosis on pulmonary endothelial injury and repair following sepsis. Am. J. Physiol. Lung Cell. Mol. Physiol. 2017, 312, L441-L451. [CrossRef]

32. Song, P.; Li, W.; Xie, J.; Hou, Y.; You, C. Cytokine storm induced by SARS-CoV-2. Clin. Chim. Acta 2020, 509, 280-287. [CrossRef] 
33. Gilardini Montani, M.S.; Falcinelli, L.; Santarelli, R.; Granato, M.; Romeo, M.A.; Cecere, N.; Gonnella, R.; D’Orazi, G.; Faggioni, A.; Cirone, M. KSHV infection skews macrophage polarisation towards M2-like/TAM and activates Ire1 alpha-XBP1 axis up-regulating pro-tumorigenic cytokine release and PD-L1 expression. Br. J. Cancer 2020, 123, 298-306. [CrossRef]

34. Rojas-Rivera, D.; Delvaeye, T.; Roelandt, R.; Nerinckx, W.; Augustyns, K.; Vandenabeele, P.; Bertrand, M.J.M. When PERK inhibitors turn out to be new potent RIPK1 inhibitors: Critical issues on the specificity and use of GSK2606414 and GSK2656157. Cell Death Differ. 2017, 24, 1100-1110. [CrossRef]

35. Yu, M.; Wang, H.; Ding, A.; Golenbock, D.T.; Latz, E.; Czura, C.J.; Fenton, M.J.; Tracey, K.J.; Yang, H. HMGB1 signals through toll-like receptor (TLR) 4 and TLR2. Shock 2006, 26, 174-179. [CrossRef]

36. Hsu, A.C.Y.; Wang, G.; Reid, A.T.; Veerati, P.C.; Pathinayake, P.S.; Daly, K.; Mayall, J.R.; Hansbro, P.M.; Horvat, J.C.; Wang, F.; et al. SARS-CoV-2 Spike protein promotes hyper-inflammatory response that can be ameliorated by Spike-antagonistic peptide and FDA-approved ER stress and MAP kinase inhibitors in vitro. Biorxiv 2020. [CrossRef]

37. Boukhvalova, M.S.; Mortensen, E.; Mbaye, A.; Lopez, D.; Kastrukoff, L.; Blanco, J.C.G. Herpes Simplex Virus 1 Induces Brain Inflammation and Multifocal Demyelination in the Cotton Rat Sigmodon hispidus. J. Virol. 2019, 94. [CrossRef] [PubMed]

38. Khan, G. Epstein-Barr virus and the germinal center B cells. Exp. Hematol. 2006, 34, 695-696. [CrossRef] [PubMed]

39. Wu, Z.X.; Chen, F.S.; Zhou, X.L.; Huang, Q.; Zhang, S.A.; Wu, H.C.; Cai, L.R.; Zeng, Z.Y.; Li, Y.H.; Li, D.L. Tenofovir and telbivudine combination therapy rapidly decreases viral loads in immune-tolerant chronic hepatitis B patients awaiting assisted reproduction: An open-label, randomized, controlled study. Eur. J. Gastroenterol. Hepatol. 2019, 31, 832-835. [CrossRef] [PubMed]

40. Cho, H.K.; Kim, S.Y.; Kyaw, Y.Y.; Win, A.A.; Koo, S.H.; Kim, H.H.; Cheong, J. HBx induces the proliferation of hepatocellular carcinoma cells via AP1 over-expressed as a result of ER stress. Biochem. J. 2015, 466, 115-121. [CrossRef]

41. Cheng, Y.L.; Lin, Y.S.; Chen, C.L.; Tsai, T.T.; Tsai, C.C.; Wu, Y.W.; Ou, Y.D.; Chu, Y.Y.; Wang, J.M.; Yu, C.Y.; et al. Activation of Nrf2 by the dengue virus causes an increase in CLEC5A, which enhances TNF-alpha production by mononuclear phagocytes. Sci. Rep. 2016, 6, 32000. [CrossRef] [PubMed] 